\title{
PERSPEKTIF RASUL PAULUS TENTANG BERBAHASA ROH BERDSARKAN 1 KORINTUS 14
}

Sarwono

sarwono@sttab.ac.id

\begin{abstract}
The gift of speaking in tongues is a message to the body of Christ which is given in tongues and is not understood by the user. Therefore, it must be followed by an interpretation by the language understood by the congregation. The gift of tongues is usually news of a prophecy for the Lord's church and must be followed by an interpretation. If the gift of tongues is not followed by an interpretation, it cannot build up the church. Therefore, the author will discuss the apostle Paul's perspective on tongues based on 1 Corinthians 14.
\end{abstract}

Keywords: Perspective, Speaking in Spirit.

Abstraksi: $\quad$ Karunia berbahasa roh merupakan suatu pesan ke pada tubuh Kristus yang diberikan dalam bahasa roh dan tidak dimengerti oleh si pemakai. Oleh karena itu, harus diikuti oleh suatu penafsiran oleh bahasa yang dimengerti oleh jemaat. Karunia bahasa roh biasanya merupakan berita suatu nubuatan bagi jemaat Tuhan dan harus diikuti oleh suatu penafsiran. Apabila karunia bahasa roh tresebut tidak diikuti oleh suatu penafsiran maka tidak dapat membangun jemaat. Oleh sebab itu, penulis akan membahas perspektif rasul paulus tentang bahasa roh berdasarkan 1 Korintus 14.

Kata Kunci: Perspektif, Berbahasa Roh.

\section{LATAR BELAKANG SURAT 1 KORINTUS}

Surat paulus yang pertama kepada jemaat di Korintus merupakan salah satu dari ke tiga surat 1 dan 2 Korintus serta Roma yang menepati posisi sentral dalam bagian Perjanjian Baru. ${ }^{1}$ Surat 1 Korintus adalah bagian dari sebuah korespondensi panjang antara paulus dan orang-orang Kristen di Korintus. Dari apa yang berhasil dilestarikan melalui kosespondensinya, kita mendapatkan sebuah gambaran yang baik tentang Paulus sebagai seorang gembala.

Ada kemungkinan besar bahwa surat 1Korintus ini ditulis untuk membalas surat dari jemaat Korintus itu sendiri (1 Korintus 7:1). Selain itu, Rasul Paulus juga sudah mendapat tentang keadaan jemaat di Korinus dari Apolos dan dari beberapa orang yang lain, khususnya dari keluarga Kleo. ${ }^{2}$ Sebenarnya setiap pasal dalam surat ini mengemukakan suatu masalah yang menyebabkan surat ini ditulis oleh Rasul Paulus. Tidak ada surat lain yang membicarakan begitu banyak masalah seperti surat ini. Rasul Paulus menulis surat ini

\footnotetext{
${ }^{1}$ John Drane, Memahami Perjanjian Baru (Jakarta:Gunung Mulia, 1996), 346

2 J. Wesley Brill, Tafsiran Surat Korintus Pertama (Bandung: Kalam Hidup, 1997), 15
} 
untuk memperbaiki kesalahan-kesalahan yang terjadi di dalam jemaat Korintus, dan utnu menjawab semua perlawanan guru-guru palsu yang mengacaukan jemaat itu dan yang menentang hak kerasulan Paulus.

\section{Keadaan Kota Korintus}

Korintus merupakan salah satu kota penting di dunia Perjanjian Baru. Korintus merupakan nama sebuah kota di Negara Yunani Ludwing dalam Olla Tulluan menyebtkan bahwa kota Korintus terletak di wilayah Akhaya, dekat selat yang memisahkan tanah daratan dari peloppones, yaitu sebuah semenanjung yang merupakan bagian selatan dari Yunani. ${ }^{3}$ Korintus adalah tempat perniagaan yang sangat ramai karena letaknya strategis dan juga menjadi pusat perdagangan antara Italia dan Asia Barat. ${ }^{4}$ letaknya srategis membuat penduduknya yang mayoritas bermata pencaharian sebagai pedagang, baik perdagang dalam negeri maupun ekspor-impor dengan negeri-negeri lain. Brill mengatakan bahwa kekayaan penduduk kota Korintus itulah yang menyebabkan mereka menjadi banyak berbuat dosa dan mereka juga menyembah dewi venus (dewi cinta berdasarkan nafsu). ${ }^{5}$ Pengaruh yang kuat dari penganut dewi venus membuat penduduk semakin sering berbuat dosa. Baxter mengatakan bahwa dalam perzinahan kota Korintus terkenal nomor satu. ${ }^{6}$

Jadi sangat tepat jika di dalam 1 Korintus 6:10 Paulus menyebutkan bahwa orang cabul, perzinah tidak mendapat bagian dalam kerajaan Allah. Jemaat Korintus sudah meninggalkan penyembahan berhala dan berbakti kepada Allah. Akan tetapi mereka masih terpengaruh dengan masyarakat yang belum mengenal Kristus dengan sungguh-sungguh sehingga mereka kembali kepada kehidupan lama. Pfitzner menjelaskan bahwa jemaat Korintus melakukan banyak kesalahan, terkhusus dalam penggunaan karunia bahasa roh. ${ }^{7}$ Jadi, orang-orang Korintus membanggakan dirinya sebagai orang yang rohani dan merasa lebih unggul karena pengalaman dan kesanggupan mereka dalam bidang rohani.

\section{Waktu dan Tempat Penulisan}

Mengenai waktu dan tempat penulisan bebarapa penafsiran Alkitab memiliki pandangan yang berbeda. Duyverman mengatakan bahwa surat 1 Korintus ditulis sekitar tahun 55M. ${ }^{8}$ untuk menegasakan waktu penulisan surat ini, Pfizner memperkirakan bahwa

\footnotetext{
${ }^{3}$ Olla Touluan, Introduksi Perjanjian Baru (Malang: Yppi, 1999), 193

${ }^{4}$ M.E. Duyverman, Pembibing Ke Dalam Perjanjian Baru (Jakara: Gunung Mulia), 98

5 J. Wesley Brill, Tafsiran Surat Korintus Pertama..., 11

${ }^{6}$ J. Sidlow Baxter, Menggali Isi Alkitab Roma-Wahyu (Jakarta:Ybk, 2002), 55

${ }^{7}$ V.C. Pfitzner, Ulasan Atas 1 Korintus Kestuan Dalam Kepelbagian..., 5

${ }^{8}$ M.E. Duyverman, Pembimbing Ke Dalam Perjanjian Baru..., 112
} 
Paulus menulis surat menjelang akhir persinggahannya di Efesus yaitu tahun 55M. ${ }^{9}$ sedangkan Brill memperkirakan bahwa surat ini ditulis sekitar tahun 56 atau 57M dan surta ini ditulis oleh Rasul Paulus ketika ia berada di Efesus. ${ }^{10}$ Berdasarkan tempat penulisan Marxsen menjelaskan bahwa surat 1 Korintus ditulis sekitar tahun $55 \mathrm{M}$ dan ditulis di kota Efesus.

\section{Struktur Kitab}

Para ahli memberikan pembagian garis-garis besar surat 1 Korintus berdasarkan bagaimana mereka memandang kitab ini. Dengan demikian tidak mengherankan jika apra ahli memberikan garis besar yang berbeda. Mengenai hal ini, Harrop ${ }^{11}$ adalah salah satu yang memberikan garis-garis besar surat 1 Korintus sebagai berikut:

a.Salam dan pengantar (1:1-9)

b. Perpecahan jemaat; ajaran Paulus dibandingkan ajaran Apolos (1:10-4:21)

c. Suatu kejadian mesum (5:1-13)

d. Ketidaklayakan pergi ke pengadilan secular, peringatan lebih lanjut terhadap kemesuman (6:1-20)

e.Pembicaraan tentang perkawinan (7:1-40)

f. Persoalan tentang danging yang dipersembahkan kepada berhala; tafsiran Paulus yang praktis mengenai pelayanan rasuli (8:1-11:1)

g. Pembentulan terhadap ketidakteraturan dalam perkumpulan ibadah; tutup kepala wanita; pesta kasih; perjamuan kudus (11:2-34)

h. Karunia-karunia Rohani $(12: 1-31 ; 14: 1-40)$

i. Cita-cita yang benar; kasih Kristen (13:1-13)

j. Ajaran risten yang benar tentang kebangkitan orang mati (15:1-58)

k. Petunjuk tentang pengumpulan persembahan bagi Yerusalem; peringatan yang bermacam-macam; salam penutup (16:1-24).

\section{EKSEGETIKAL 1 KORINTUS 14:1-40}

Dalam bab ini penulis akan menjelaskan tentang study eksegesis berdasarkan struktur teks serta penulisan akan lebih dalam menggali dan menjelaskan bagaimana perspektif Paulus tentang bahasa roh.

\footnotetext{
${ }^{9}$.C. Pfitzner, Ulasan Atas 1 Korintus Kestuan Dalam Kepelbagian..., 10

${ }^{10}$ J. Wesley Brill, Tafsiran Surat Korintus Pertama..., 19

11 J.H. Haroop, "Korintus" Dalam J.D. Douglas (Ed), Ensiklopedia Alkitab Masa Kini Jilid I (Jakarta: Omf, 1995), 582
} 


\section{Kejarlah Kasih}

Bagaimana ini Rasul Paulus mengawalinya dengan kata kejarlah. Dalam Kamus Besar Bahasa Indonesia kata "kejarlah" berasal dari kata kerja yang berarti berlari-lari, bersusah payah hendak mencapai. ${ }^{12}$ Dalam bahasa Yunani, kata "kejarlah" adalah diwkete dari akar kata $\delta \iota \omega \kappa \omega(\text { dioko })^{13}$ artinya mengejar, berlari, menganiaya, mengusi, mencari. ${ }^{14}$ Kata ini dipakai dalam bentuk kata kerja present imperaktif aktif plural, sebagai kata yang menunjukkan, tindakan yang tengah berlangsung. Dalam KJV memakai kata pursue yang berarti setelah mengikuti. ${ }^{15}$ Dalam NAS memakai kata pursue dengan arti: mengejar kebahagiaan, mengikuti, meneruskan perjalanan. ${ }^{16}$ Jadi dengan demikian arti secara harafiah adalah orang kristen yang mengejar kebahagiaan harus memiliki tindakan untuk memiliki kasih.

Teks ini menjelaskan bahwa jika setiap orang kristen berkeinginan untuk bahagia maka ada tindakan yang harus dilakukan yaitu mengejar kasih. Paulus membuka pasal ini dengan frasa "Kejarlah Kasih", Paulus masih mengaitkan frase ini dengan konteks ini dengan pasal yang sebelumnya. Paulus mnekankan untuk mengejar kasih, sebagai hal yang sangat penting diantara karunia-karunia roh.

Kata "kejarlah" merupakan istilah yang lebih kuat dari pada kata "usahakanlah". 17 Usaha adalah keigatan untuk mengerahkan tenaga, pikiran untuk mencapai suatu maksud sementara kaa kejar adalah susul dengan berlari. Dari pernyataan di atas menunjukkan bahwa mengejar kasih menjadi dasar yang penting dalam sebuah pertobatan dalam karunia roh itu tida selalu menjadi hal yang penting di dalam sebuah pertobatan. Evans mengatakan bahwa hal yang harus diingat adalah Paulus menyatakan bahwa hal yang perlu dikejar adalah kasih dan bukan karunia ini dan karunia itu. ${ }^{18}$ Dalam konteks ini berkaitan dengan pembahasan Paulus mengenai bahasa roh. Paulus menyarankan supaya setiap jemaat mengejar kasih bukan karunia. Paulus juga mengarahkan jemaat yang ada di Korintus untuk mengenal karunia rohani amna yang harus mereka utamakan. Selama

\footnotetext{
${ }^{12}$ Daniel Haryono, Kamus Besar Bahasa Indonesia (Jakarta: Pustaka Phoenix, 2012) 428

${ }^{13}$ Hasan Susanto, Perjanjian Baru Interlinear Yunani Indonesia Dan Konkordansi Alkitab Pb Jilid I (Jakarta:Lai, 2006) 934)

${ }^{14}$ Hasan Susanto Perjanjian Baru Interlinear Yunani Indonesia Dan Konkordansi Alkitab Pb Jilid II (Jakarta:Lai, 2006), 218

${ }^{15}$ Spiros Zodhiates, The Hebrew-Greek Key Study Bible, 1405

${ }^{16}$ Robert, L. Thomas, Exhaustive Concordance Of The Bible (Amerika: Holman, 1977), 1643

${ }^{17}$ Lewis Jhonson, "1 Korintus" dalam Charles Pfeiffer dan Everentt F Horison (Ed), The Wiclife Bible Comentary (Malang: Gandum Mas, 2001), 608

${ }^{18}$ Tony Evans, Janji Allah (Jakarta: Immanuel, 1999), 316
} 
mereka mengejar kasih dan menjadikan sikap kristiani ini sebagai tujuan utama, mereka boleh giat mengejar karunia-karunia rohani dan mendambakannya dalam batas tertentu.

Rasul Paulus berkeinginan supaya setiap jemaat mengejar kasih bukan karunia, kata "kasih" dalam bahasa Yunani $\alpha \gamma \alpha \pi \epsilon \nu$ (agapen) dari kata dasar $\alpha \gamma \alpha \pi \epsilon$ (agape) dalam bentuk (Non acusatif feminimne singular) kata benda tunggal. ${ }^{19}$ Dalam terjemahan KJV memakai kata charity yang berarti kemurahan hati tanpa balas. ${ }^{20}$ Dalam Perjanjian Baru paling umum digunakan untuk kata kasih agape. Palmer menjelaskan bahwa "Kasih" berarti yang paling tinggi dan paling mulia, terjemahan ini cenderung diambil dari LXX yang menggambarkan kasih Allah kepada manusia dan kasih manusia kepada sesamanya. ${ }^{21}$ Jadi dari pernyataan di atas, agape dapat diartikan sebagai kata yang digunakan untuk menyatakan kasih yang tertinggi dan yang tidak dapat dibalas oleh siapa pun. Kasih itu menunjukkan kepada kasih yang paling tinggi, kasih yang tulus, seperti kasih Allah kepada manusia.

Rasul Paulus menggunakan frasa "Kejarlah Kasih" dilatarbelakangi oleh jemaat Korintus yang berperilaku buruk. Evans mengatakan bahwa jemat Korintus hanya mengejar karunia dan memamerkan karunia tersebut, dalam hal ini yang dimaksud adalah karunia berbahasa roh, jika dilihat secara pribadi mereka tidak memiliki kasih dan tidak mengejar kasih itu. ${ }^{22}$ Berarti dapat disimpulkan bahwa karunia apa pun tanpa kasih tidak ada manfaatnya (bnd. I Korintus 13:1).

Rasul Paulus menggunakan kata agape yang nerupakan hal yang tertinggi. Kasih yang dimaksud Rasul Paulus adalah kasih yang nyata dalam perkataan, perbuatan dan dapat membangun. Kasih yang membangun pada pad kenyataan lebih bermanfaat dibandingkan dengan karunia bahasa roh.

\section{Usahakanlah Dirimu Memperoleh Karunia-Karunia Roh}

Kata berikutnya yang ditekankan oleh Paulus setelah kata "kejarlah" adalah kata "usahakanlah". Dalam KBBI kata "usahakanlah" memiliki arti pekerjaan, perbuatan, daya

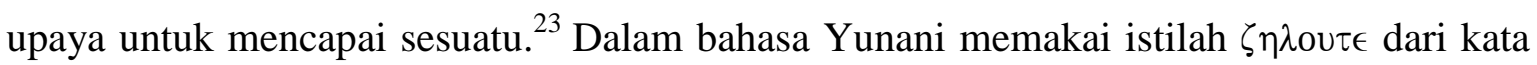
dasar $\zeta \eta \lambda o \omega$ (zeloo) dalam bentuk (verb imperactive peresent active $2^{\text {nd }}$ person plural) kata kerja untuk orang kedua jamak yang menyatakan suatu pekerjaan yang berhubungan

\footnotetext{
${ }^{19}$ Hasan Susanto Perjanjian Baru Interlinear Yunani Indonesia Dan Konkordansi Alkitab Pb Jilid I..., 934

${ }^{20}$ Sudrajad \& Farida, kamus Lengkap Bahasa Inggris (Semarang: Widya Karya, 1999), 71

${ }^{21}$ Palmer, "Kasih" dalam JD. Douglas (Ed), Ensiklopedia Alkitab Masa Kini Jilid 1 A-L (Jakarta: YKBK, 2001), 525

${ }^{22}$ Tony Evans, Janji Allah ..., 356

${ }^{23}$ Daniel Haryono, Kamus Besar Bahasa Indonesia ..., 927
} 
dengan tindakan yang tengah berlangsung. Dari kata $\zeta \eta \lambda o \omega$ (zeloo) yang artinya giat, bersemangat, tekun. ${ }^{24}$ Dalam versi KJV memakai kata Desire yang berarti menginginkan, meminta. ${ }^{25}$ Demikian juga dalam versi NAS dan NIV menggunakan kata yang sama. Berkaitan dengan ayat ini kata "usahakanlah" tidak lebih tinggi dari kata "kejarlah". Evans mengatakan bahwa ketika Paulus mengatakan untuk mengejar kasih, dalam penekanannya berbeda dengan penyataannya yang mengutamakan "usahakanlah",26

Dari penyataan di atas dapat kita simpulkan bahwa Rasul Paulus menekankan bahwa kasih merupakan hal utama yang harus dikejar oleh setiap orang percaya. Dalam menanggapi pendapat evans, suhento mengatakan, jika berbicara tentang karunia Rasul Paulus tidak menggunakan istilah "kejarlah" atau dalam bahasa Yunani $\delta \iota \omega \kappa \in \tau \in$ (diokete),

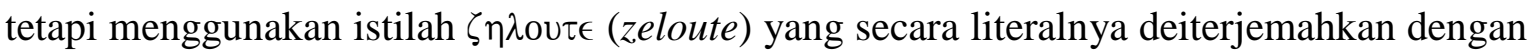
arti "rindukanlah". ${ }^{27}$ Jadi dari pernyataan ini Rasul Paulus mengahrapkan agar jemaat Korintus rindu untuk memiliki karunia rohani. Donald dan Davis lebih menegaskan lagi secara spesifik bahwa Rasul Paulus mengatakan yang harus dirindukan untuk dimiliki adalah karunia bernubuat bukan bahasa roh. ${ }^{28}$ Jadi dari beberapa penyataan di atas dapat disimpulkan bahwa Rasul Paulus menekankan agar jemaat Korintus mengutamakan karunia bernubuat daripada karunia bahasa roh, sebab karunia bahasa roh tidak ada faedahnya bagi orang lain jika tidak ada yang menafsirkan (bnd. Ay. 5, 28). Tetapi karunia bernubuat itu lebih bermanfaat bagi orang lain, khususnya dalam pertemuan jemaat.

'Dalam konteks ini, kata bernubuat yang diapakai dalam bahasa Yunani adalah

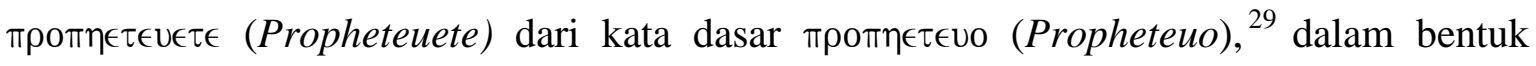
(verb subjunctive present active $2^{\text {nd }}$ person plural) yang menyatakan suatu pekerjaan orang kedua jamak. Dalam terjemahan versi KJV, kata bernubuat diterjemahkan dengan kata prophesy, demikian juga dalam versi NIV dan versi NAS menggunakan kata yang sama yaitu prophesy yang berarti nubuat. Dalam suratnya Rasul Paulus di jemaat Korintus mengatakan bahwa jika mereka merindukan atau berusaha memiliki karunia hendaklah memiliki karunia bernubuat.

${ }^{24}$ James Strong, Strong Exhaustive Concordance Of The Bible (New York: Thomas Nelson Publisher, 1979), 34

${ }^{25}$ Spiros Zodhiates, The Hebrew-Greek Key Study Bible, 1405

${ }^{26}$ Tony Evans, Janji Allah..., 356

${ }^{27}$ Suhento Liaw, Hermeneutik: Cara Menafsirkan Alkitab, (Jakarta: STT Agape, 1998), 104 1972), 144

${ }^{28}$ Donald Bridge dan Davis Pypers, Karunia-karunia Roh dan Jemaat (Bandung: Kalam Hidup, I..., 935

${ }^{29}$ Hasan Susanto, Perjanjian Baru Interlinear Yunani Indonesia dan konkordansi Alkitab PB Jilid 
Yang menjadi pertanyaaannya sekarang adalah mengapa harus karunia bernubuat yang utama harus dimiliki?. Pada ayat ketiga Paulus mengatakan bahwa siapa yang bernubuat, ia berkata-kata kepada manusia. Artinya adalah orang yang menyampaikan pesan Allah yang bersifat membangun, menasihati serta menghibur. Mengenai hal bernubuat ini, Baker berpendapat bahwa tujuan khotbah dapat dikatakan mirip dengan tujuan nubuat, akan tetapi ada suatu perbedaan dasar yaitu bahwa nubuat terjadi akibat suatu ilham langsung dari Allah sedangkan khotbah merupakan uraian berdasarkan Firman Allah yang dicetuskan oleh manusia. ${ }^{30}$ Daun juga berpendapat bahwa karunia bernubuat pada masa sekarang ini identik dengan berkhotbah atau memiliki tujuan yang yang sama yang juga menyatakan, menguraikan, dan menjelaskan kehendak Allah. ${ }^{31}$

Oleh karena itu dalam konteks ini, Rasul paulus mengharapkan kepada jemaat di Korintus untuk mengutamakan memperoleh karunia bernubuat. Sama halnya seperti yang dijelaskan di atas bahwa karunia bernubuat membangun, menasihati dan menghibur. Dan saat ini karunia bernubuat sangat relevan, sama dengan berkhotbah karena memiliki tujuan yang sama. Rasul Paulus mengatakan kepada jemaat di Korintus harus mengejar kasih dan mengusakan karunia bernubuat dengan tujuan yang sama yaitu agar karunia itu bermanfaat bagi diri sendiri dan orang lain.

\section{Bahasa Roh}

Bahasa roh dalam bahasa Yunani adalah $\gamma \lambda \omega \sigma \sigma \alpha$ (glossa) yang berasal dari kata dasar $\gamma \lambda \omega \sigma \sigma \alpha$ (glossa) $^{32}$ dalam bentuk (noun dative feminine singular) kata benda tunggal yang menunujukan seorang pribadi yang ikut serta secara tak langsung pada sebuah tindakan. Dalam versi KJV menggunakan kata speaketh unknown tongue ${ }^{33}$ yang artinya perkataan bahasa lidah yang dimaksud dari terjemahan di atas adalah suatu perkataan yang tidak dimengerti maksud atau arti dari perkataan itu sendiri, sebab seorang yang berkatakata dengan bahasa roh tidak berkata-kata kepada manusia, tetapi kepada Allah.

Ada orang yang berpendapat bahwa berkata-kata dengan bahasa roh merupakan pengucapan satu kata yang ada kaitannya dengan bahasa manusia. Stephen Tong berpendapat bahwa istilah glossa yang ditulis kurang lebih 50 kali dalam Perjanjian Baru,

\footnotetext{
${ }^{30}$ David L. Baker, Roh dan Kerohanian Dalam Jemaat (Jakarta: Gunung Mulia, 2009), 129

${ }^{31}$ Paulus Daun, Pengantar Ke Dalam Homeletika (manado: Yayasan daun Family, 2003), 5

${ }^{32}$ Hasan Susano, Perjanjian Baru Interlinear Yunani Indonesia dan Konkordansi Alkitab PB Jilid I..., 935

${ }^{33}$ Spiros Zodhiates, The Hebrew-Greek Key Study Bible, 1405
} 
semuanya berrati bahasa, dan bukan bunyi tanpa arti. ${ }^{34}$ Dengan demikian, bahwa bahasa lidah atau bahasa roh mengacu kepada bahasa logat manusia bukan bunyi yang tak berarti.

Dalam konteks 1 Korintus ini Paulus memberikan banyak penjelasan mengenai penggunaan karunia bahasa roh. Penjelasan yang diberikan Rasul Paulus kepada jemaat Korintus berkenaan dengan penyalahgunaan karunia bahasa roh. Putman menjelaskan bahwa orang-orang Korintus menambahkan nilai lebih dan menyalahgunakan glossolalia, sehingga Rasul Paulus dengan tegas membatasi pemakaiannya di muka umum (ayat 27-28) dan menekankan nilai nubuat bagi seluruh gereja (ayat $1 \& 5$ ). ${ }^{35}$ Pada ayat 2, 4 dan 5, Rasul Paulus membandingkan kembali karunia bahasa roh dengan karunia bernubuat. Ini adalah salah satu evaluasi bahwa nubuat diutamakan daripada bahasa roh, keculi kalau bahasa roh tersebut ditafsirkan.

Evans mengatakan bahwa orang Korintus selalu mengejar karunia bahas roh atau bahasa lidah hanya untuk dipamerkan dan bukan untuk membangun. ${ }^{36}$ Pendapat ini dapat dibuktikan dalam ibadah-ibadah jemaat Korintus yang sangat mengagumkan karunia bahasa roh, sehingga terjadi kekacauan dalam pertemuan jemaat, akibat dari semua jemaat yang hadir mengucapkan bahasa roh. Pada ayat ke-6 Rasul Paulus masih membahas tentang bahasa roh. Terkait dengan ayat ini Brill menjelaskan bahwa Rasul Paulus menyebutkan empat hal yang berfaedah bagi jemaat yaitu penyataan Allah, pengetahuan, nubuat dan pengajaran. ${ }^{37}$ Dalam konteks ini Rasul Paulus menununjukkan betapa siasianya memamerkan kemampuan berbicara dalam bahasa yang tidak bisa dikenal dan tidak dimengerti dalam pertemuan jemaat. Itu sama sekali tidak bermanfaat. Rasul Paulus mencontohkan dirinya sendiri yang tidak ada artinya jika datang hanya dengan bahasa asing yang tidak ditafsirkan, tanpa menyampaikan penyataan Allah, pengetahuan, nubuat atau pengajaran.

Pada ayat selanjutnya (7-8), Rasul Paulus menggunakan ilustrasi alat-alat musik, yang memiliki bunyi yang berbeda. Dalam kontek ini Hillyer berpendapat bahwa Rasul Paulus melukiskan perlunya bahasa asing ditafsirkan di depan umum, seperti sebuah lagu tidak dapat dikenal jika notnya tidak mudah didengar. ${ }^{38}$ Jadi, dari ilustrasi ini Rasul Paulus dengan keras menegur jemaat Korintus terkait dengan penyalahgunaan karunia bahasa roh.

\footnotetext{
${ }^{34}$ Stephen Tong, Roh Kudus, Doa dan Kebangunan ..., 46

${ }^{35}$ W.F. Putman, "Bahasa Roh", dalam JD. Douglas (Ed), Ensklopedia Alkitab Masa Kini Jilid I AL..., 133

${ }^{36}$ Tony Evans, Janji Allah..., 455

${ }^{37}$ J. Wesley Brill, Tafsiran Surat Korintus Pertama..., 257

${ }^{38}$ Norman Hillyer, "1Korintus" dalam Donald Guthrie (Ed), Tafsiran Alkitab Masa Kini Jilid 3..., 
Pada ayat yang ke 39-40 Rasul Paulus mengatakan bahwa "jangan melarang orang yang berkata-kata dalam bahasa roh", tetapi segala sesuatu harus berlangsung dengan sopan dan teratur. Dalam menanggulangi kesalahan atau penyalahgunaan bahasa roh bukan melarang untuk tidak berbahasa roh melainkan menunjukkan penggunaan yang benar.

\section{Ia Harus Berdoa Supaya Ada Yang Menafsirkannya}

Pada bagian ini Rasul Paulus memberikan aturan yang sangat tegas. Kata "ia harus

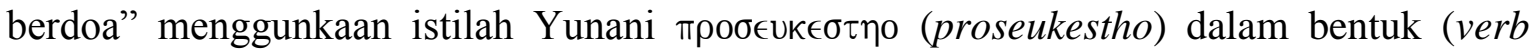
imperative present middle $3^{\text {rd }}$ person singular) kata kerja imperative orang ketiga tunggal. ${ }^{39}$ Dalam terjemahan NIV menggunakan kata shoul pray, dengan arti seharusnya, sebaiknya berdoa. Jhonson menerjemahkan istilah di atas dengan kata "memohon". 40 Jadi, terjemahan di atas Rasul Paulus menghendaki agar siapa yang berkata-kata dalam bahasa asing hendaknya juga sebaiknya berdoa dan memohon agar diberikan karunia menafsirkan.

Dalam hal ini Brill menerjemahan maksud dari Rasul Paulus sebagai berikut: jika kamu memberikan dirimu dipimpin olh Roh Kudus untuk berdoa dengan bahasa asing atau bahasa yang ahrus ditafsirkan, kamu harus melakukannya dengan satu tujuan, yaitu bahwa kamu juga dapat menafsirkan. ${ }^{41}$ Untuk menanggapi pernyataan di atas Hillyer menambahkan karunia menafsirkan hendaknya dicari utnuk memperluas bahasa roh. $^{42}$ Rasul Paulus mengharapkan agar siapa yang berbahasa asing seharusnya juga memohon karunia untuk menafsirkan, supaya karunia bahasa roh itu dapat berfaedah untuk membangun orang lain, terlebih dalam pertemuan jemaat. Jadi penekanan Rasul Paulus dalam ayat ini adalah memohon untuk karunia menafsirkan juga.

Setiap karunia berasal dari Allah, demikian juga dengan karunia menafsirkan. Di dalam 1 Korintus 14 ini, beberapa kali Rasul Paulus mengulang kata ini (ayat 13, 16, 27 , 28) dan selalu dikaitkan dengan karunia bahasa roh. Karunia menafsirkan menggunakan istilah Yunani $\delta\left\llcorner\in \rho \mu \in \nu \in \cup \in \eta\right.$ (diermeneue), dalam bentuk kata kerja imperative. ${ }^{43}$ Dalam terjemahan KJV, NAS dan NIV menerjemahkan dengan kata interpret, dengan arti

\footnotetext{
${ }^{39}$ Hasan Susano, Perjanjian Baru Interlinear Yunani Indonesia dan Konkordansi Alkitab PB Jilid I..., 937

${ }^{40}$ Lewis Jhonson, "1 Korintus" dalam Charles Pfeiffer dan Everentt F Horison (Ed), The Wiclife...,848

${ }^{41}$ J. Wesley Brill, Tafsiran Surat Korintus Pertama..., 276

${ }^{42}$ Norman Hillyer, "1Korintus" dalam Donald Guthrie (ed), Tafsiran Alkitab Masa Kini Jilid 3(Jakarta: YKBK, 2006), 506 I..., 939

${ }^{43}$ Hasan Susano, Perjanjian Baru Interlinear Yunani Indonesia dan Konkordansi Alkitab PB Jilid
} 
menerjemahkan. ${ }^{44}$ Setiap karunia yang diberikan Allah memiliki tujuan tertentu. Oleh karena itu, agar tujuannya lebih jelas maka karunia itu harus ditafsirkan. Ryrie mengatakan ada dua tujuan bahasa lidah atau bahasa asing yaitu untuk menyampaikan kebenaran Allah dan untuk membuktikan kebenaran berita Kristen terutama orang-orang Yahudi (bnd $14: 5,21,22){ }^{45}$

\section{KESIMPULAN}

Teks ini menjelaskan bahwa jika setiap orang kristen berkeinginan untuk bahagia maka ada tindakan yang harus dilakukan yaitu mengejar kasih. Paulus membuka pasal ini dengan frasa "Kejarlah Kasih", Paulus masih mengaitkan frase ini dengan konteks ini dengan pasal yang sebelumnya. Paulus menekankan untuk mengejar kasih, sebagai hal yang sangat penting diantara karunia-karunia roh.

Rasul Paulus mengharapkan agar siapa yang berbahasa asing seharusnya juga memohon karunia untuk menafsirkan, supaya karunia bahasa roh itu dapat berfaedah untuk membangun orang lain, terlebih dalam pertemuan jemaat. Jadi penekanan Rasul Paulus dalam ayat ini adalah memohon untuk karunia menafsirkan juga.

${ }^{44}$ Spiros Zodhiates, The Hebrew-Greek Key Study Bible, 1405

${ }^{45}$ Charles Ryrie, Theologi Dasar 2 (Yogyakarta: ANDI, 2004), 155 


\section{DAFTAR PUSTAKA}

Bridge, Donald, dan Davis Pypers. (1972). Karunia-karunia Roh dan Jemaat, Bandung: Kalam Hidup.

Daun, Paulus. (2003). Pengantar Ke Dalam Homeletika,Manado: Yayasan Daun Family.

Drane, John. (1996). Memahami Perjanjian Baru, Jakarta: BPK Gunung Mulia.

Duyverman, M. E. (----). Pembibing Ke Dalam Perjanjian Baru, Jakara: Gunung Mulia.

Evans, Tony. (1999). Janji Allah, Jakarta: Immanuel.

Haroop, J. H. (1995). “Korintus” Dalam J.D. Douglas (Ed), Ensiklopedia Alkitab Masa Kini Jilid I Jakarta: OMF.

Haryono, Daniel. (2012). Kamus Besar Bahasa Indonesia, Jakarta: Pustaka Phoenix.

Jhonson, Lewis. (2001). "1 Korintus" dalam Charles Pfeiffer dan Everentt F. Horison (Ed), The Wiclife Bible Comentary, Malang: Gandum Mas.

L. Baker, David. (2009). Roh dan Kerohanian Dalam Jemaat, Jakarta: Gunung Mulia.

L. Thomas, Robert. (1977). Exhaustive Concordance Of The Bible, Amerika: Holman.

Liaw, Suhentouw. (1998). Hermeneutik: Cara Menafsirkan Alkitab, Jakarta: STT Agape.

Sidlow Baxter, J. (2002). Menggali Isi Alkitab Roma-Wahyu, Jakarta: YBK.

Strong, James. (1979). Strong Exhaustive Concordance Of The Bible, New York: Thomas Nelson Publisher.

Sudrajad \& Farida. (1999). Kamus Lengkap Bahasa Inggris, Semarang: Widya Karya.

Susanto, Hasan. (2006). Perjanjian Baru Interlinear Yunani Indonesia Dan Konkordansi Alkitab PB Jilid I, Jakarta:LAI.

(2006). Perjanjian Baru Interlinear Yunani Indonesia Dan Konkordansi Alkitab PB Jilid II, Jakarta:LAI.

Touluan, Olla. (1999). Introduksi Perjanjian Baru, Malang: YPPII.

Wesley Brill, J. (1997). Tafsiran Surat Korintus Pertama, Bandung: Kalam Hidup.

Zodhiates, Spiros. (-----). The Hebrew-Greek Key Study Bible. 